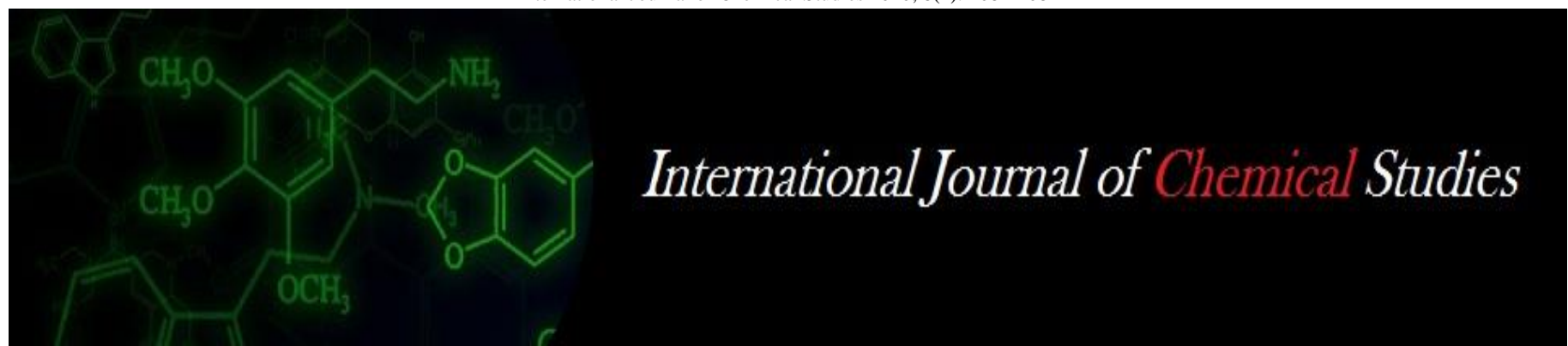

P-ISSN: 2349-8528

E-ISSN: 2321-4902

IJCS 2020; 8(1): 2082-2084

(C) 2020 IJCS

Received: 13-11-2019

Accepted: 15-12-2019

Sankarganesh E

Department of Agricultural

Entomology, BCKV, Mohanpur,

West Bengal, India

Girish AG

Plant Biosecurity Division

NIPHM, Rajendranagar,

Hyderabad, Telangana, India

Alice RP Sujeetha

Plant Biosecurity Division

NIPHM, Rajendranagar,

Hyderabad, Telangana, India

Mariadoss A

Plant Biosecurity Division

NIPHM, Rajendranagar,

Hyderabad, Telangana, India

Corresponding Author:

Sankarganesh E

Department of Agricultural

Entomology, BCKV, Mohanpur,

West Bengal, India

\section{Influence of relative humidity on phosphine concentration during aluminium phosphide (ALP) fumigation in pigeon pea}

\author{
Sankarganesh E, Girish AG, Alice RP Sujeetha and Mariadoss A
}

DOI: https://doi.org/10.22271/chemi.2020.v8.i1ae.8572

\begin{abstract}
Phosphine fumigant is widely used to control stored insect pest infestation in grains. The study on Aluminium Phosphide (ALP) fumigation was conducted to find out the effect of relative humidity on concentration of phosphine. Aluminium phosphide (tablet) $56 \%$ formulation was used for fumigation of two stacks of pigeon pea grains, each of 4 MT capacities. During fumigation first stack the humidity was ranged 60 to $70 \%$ and another stack the humidity was between 50 to $60 \%$. Fumigation procedure carried out as per National Standards of Phytosanitary Measures (NSPM) with dose rate of 3 tablets / MT for 10 days exposure period. Phosphine concentration was monitored in both stacks from 1 to 10 days after fumigation. After $24 \mathrm{hrs}$ (1 day) of treatment the average phosphine concentration was $340 \mathrm{ppm}$ in stack with higher humidity and terminal concentration (after 10 days) was $315 \mathrm{ppm}$, whereas in stacks with lower humidity the concentration was $309 \mathrm{ppm}$ and $184 \mathrm{ppm}$ after $24 \mathrm{hrs}$ and 10 days respectively. The results revealed that concentration of phosphine was directly proportional to the humidity.
\end{abstract}

Keywords: Fumigation, phosphine, pigeon pea, concentration, humidity

\section{Introduction}

Phosphine (Aluminium phosphide) is one of the significant fumigant (Bell 2000) ${ }^{[1]}$ used worldwide for disinfestations of durable commodities and is in use mainly for cereals, pulses and spices (EPPO 2012) ${ }^{[2]}$ and other agricultural commodities (Rajendran and Gunasekaran, 1995) ${ }^{[3]}$. Phosphine gas evolved from the tablets or granules effectively controls the various stored product pests in storage (Rajashekar et al., 2006) ${ }^{[4]}$. But the efficacy of the fumigation or released fumigant is directly related to the outside environmental factors i.e. temperature and humidity. Numerous pests are associated with food commodities in storage, particularly in the developing countries where poor sanitation practices are followed (Talukder et al., 2004; Talukder 2005; Talukder 2006) ${ }^{[5,6,7]}$. Stored grain pests like rice weevil and pulse beetle are widespread and destructive internal feeder of cereals and pulses with the estimated postharvest loss ranged from 50\% and 30-40\% respectively (Ahmed 2010) ${ }^{[8]}$.

In order to maintain the quality in storage and export of commodities to the international market (Rajendran 2016) ${ }^{[9]}$, control of stored product pest is of foremost concern. Phosphine fumigant is widely utilizing to control insect infestation in storage and during the grain trade as a phytosanitary treatment against several insect pests. In India, the grains which meant for consumption is stored in various godowns and warehouses where fumigation is done on regular intervals to protect from pest infestation and supply of insect free products to the consumers. There relative humidity is the crucial factor which decides the success rate of the fumigation (Rajendran et al., 2001) ${ }^{[10]}$. But the information on relationship between humidity and phosphine fumigation is lacking during the monitoring of fumigant concentration. Moreover, the research on phosphine fumigation in presence of relative humidity in varied climatic conditions of India is scanty. Considering the above facts, the present investigation was carried out in field level to determine the effects of relative humidity on release of phosphine with standard concentration by using ALP (tablet) $56 \%$ formulation. 


\section{Materials and Methods \\ Bagged stacks}

The study was conducted with pigeon pea stacks of same batch with 4 MT quantities for 10 days exposure period. The experiment was conducted during the summer months where the humidity was 50 to $60 \%$ which was confirmed with the help of digital hygrometer. The humidity was increased artificially for the experiment since the humidity was low. In order to monitor the phosphine concentration in stacks, nylon monitoring lines (NSPM standard) were placed on top, middle and bottom of the stacks as described by (Rajendran et $a l ., 2001)^{[10]}$. Further, the stacks were enclosed with standard fumigation sheet to make air tight enclosures.

\section{Treatments and dosage}

To check the difference in phosphine concentration in relation to relative humidity, one stack (4MT) were surrounded with wet jute gunny bags before $24 \mathrm{hrs}$ of fumigation where the humidity was increased to 60 to $70 \%$ and another stack (4 MT) the natural humidity (50 to $60 \%)$ during the experimental period was considered as second treatment. The experiment was replicated thrice. The relative humidity was monitored with the help of digital hygrometer. In both the stacks the dose rate of 3 tablets/MT was applied in 2/3 distribution pattern (two tablets at top and one at bottom of stack) as per NSPM standard 22.

\section{Gas monitoring and leak checking}

Three monitoring lines were placed each at front base, middle centre and top back over the enclosures. Phosphine concentration was monitored at 24 hrs interval with phosphine monitor for 10 days (Table 1 and 2); leak checking was monitored at regular intervals using leak detector.

\section{Results and discussion}

The study revealed that concentration of phosphine varies gradually with humidity level. It was noticed that commodity with ALP @ 3tablets /MT having 4MT capacities for 10 days exposure periods, the average phosphine concentration ranged from 315-848 ppm (Table 1; Fig.1) with RH 60\% and above. $315 \mathrm{ppm}$ is found to be the average minimum concentration. The average phosphine concentration ranged only 184-527 ppm (Table 2; Fig.1) where the RH is $60 \%$ and below. Here, $184 \mathrm{ppm}$ is found to be the average minimum concentration. The phosphine gas concentration at initial monitoring after 24 hrs revealed that the average concentration of phosphine was $340 \mathrm{ppm}$ in stack with higher humidity and $309 \mathrm{ppm}$ in stack with lower humidity. Interestingly, the maximum phosphine concentration was achieved $3^{\text {rd }}$ day after the fumigation in both the stacks i.e. $848 \mathrm{ppm}$ and $527 \mathrm{ppm}$ (Fig.1). During $5^{\text {th }}$ day after the ALP treatment the average concentration of 616 ppm and 417 ppm was monitored, at $7^{\text {th }}$ day after the ALP treatment the average concentration of $465 \mathrm{ppm}$ and $315 \mathrm{ppm}$ was achieved in the above stacks respectively. The stacks were perfectly sealed and gas leakage was zero $\mathrm{ppm}$. The statement was in correlation with (Rajendran et al.,2001) ${ }^{[10]}$ they reported that under perfect sealing and covering of stacks with exposure of phosphine achieved maximum concentration and $100 \%$ mortality of stored grain pests.

This study was also in line with (Rajendran, 2016) ${ }^{[11]}$ who stated that terminal concentration is one of the important criteria for control of normal and phosphine resistant insects. But here the end concentration of the stack was comparatively low $(184 \mathrm{ppm})$ in the commodity fumigated with humidity range of 50 to $60 \%$ whereas the terminal concentration of 315 ppm was achieved in fumigation of commodity with humidity range of 60 to $70 \%$. The experiment conducted by (Reddy et al., 2007) ${ }^{[12]}$ with different food commodities dose at $2 \mathrm{~g} \mathrm{PH}_{3}$ per metre cube entrusted the importance of terminal concentration during the fumigation. In present study, the phosphine gas concentration was found increased in relation to the humidity. This investigation has highlighted the importance of relative humidity with regards to phosphine which will be useful for conducting the further studies on increasing the humidity at field level especially during the summer months and dry areas where the humidity is less. Further study on fumigation with monitoring of phosphine concentration with different humidity levels against storage pests especially on insects is needed to achieve greater success in fumigation.

\section{Conclusion}

This study concluded that relative humidity has played the major role in releasing the phosphine. As the humidity decreases the concentration or the release of phosphine becomes slow. India, being a tropical country having diversified climatic conditions, the humidity was less in many days in the places away from the seashores. Hence, a detailed study on different levels of humidity during fumigation period is required to develop good fumigation practices. This preliminary study will help in build-up of phosphine concentration which is required to control dreaded storage pests in the commodities.

Table 1: Concentration of phosphine gas on pigeon pea with 60 to $70 \%$ relative humidity

\begin{tabular}{|l|c|c|c|}
\hline Dose / MT & Stack IHumidity level & $\begin{array}{c}\text { Treatment } \\
\text { duration }\end{array}$ & $\begin{array}{c}\text { Average phosphine concentration } \\
\text { (Values in ppm) }\end{array}$ \\
\hline \multirow{5}{*}{3 tablets } & Day 1 & 340 \\
\cline { 3 - 4 } & \multirow{5}{*}{ Stack1/RH 60-70\% } & Day 2 & 706 \\
\cline { 3 - 4 } & & Day 3 & 848 \\
\cline { 3 - 4 } & & Day 4 & 664 \\
\cline { 3 - 4 } & & Day 5 & 616 \\
\cline { 3 - 4 } & & Day 6 & 535 \\
\cline { 3 - 4 } & & Day 7 & 465 \\
\cline { 3 - 4 } & & Day 8 & 419 \\
\cline { 3 - 4 } & & Day 9 & 370 \\
\cline { 3 - 4 } & & Day 10 & 315 \\
\hline
\end{tabular}


Table 2: Concentration of phosphine gas on pigeon pea 50 to $60 \%$ relative humidity

\begin{tabular}{|l|c|c|c|}
\hline \multirow{3}{*}{ Dose / MT } & Stack LHumidity level & $\begin{array}{c}\text { Treatment } \\
\text { duration }\end{array}$ & $\begin{array}{c}\text { Average phosphine concentration } \\
\text { (Values in ppm) }\end{array}$ \\
\hline \multirow{5}{*}{3 tablets } & Day 1 & 309 \\
\cline { 3 - 4 } & \multirow{5}{*}{ Stack 2 /RH 50-60\% } & Day 2 & 466 \\
\cline { 3 - 4 } & & Day 3 & 527 \\
\cline { 3 - 4 } & & Day 4 & 513 \\
\cline { 3 - 4 } & & Day 5 & 417 \\
\cline { 3 - 4 } & Day 6 & 352 \\
\cline { 3 - 4 } & Day 7 & 315 \\
\cline { 3 - 4 } & Day 8 & 283 \\
\cline { 3 - 4 } & & Day 9 & 232 \\
\cline { 3 - 4 } & Day 10 & 184 \\
\hline
\end{tabular}

Note: $1 \mathrm{MT}=1000 \mathrm{~kg}$

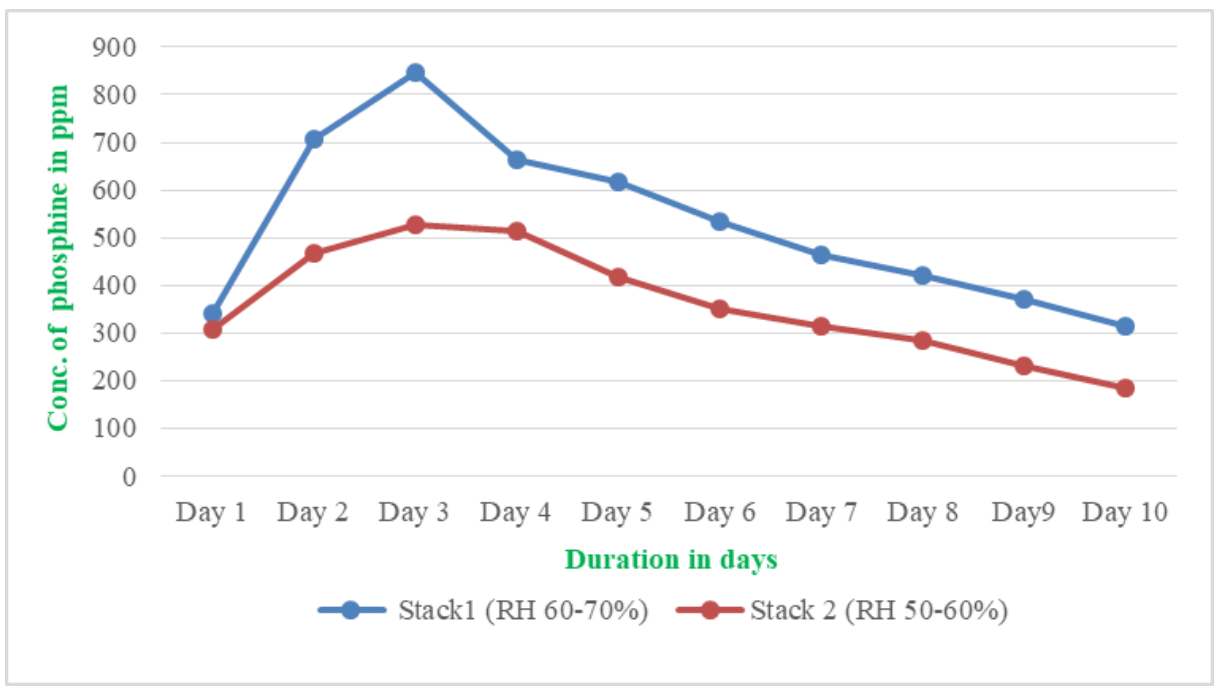

Fig 1: Concentration of phosphine gas on pigeon pea stacks at 10 days exposure period with two different relative humidity

\section{Acknowledgment}

The authors of the study grateful to Director General, National Institute of Plant Health Management (NIPHM), Hyderabad for the encouragement and support.

\section{References}

1. Bell CA. Fumigation in the $21^{\text {st }}$ century. Crop Protection. 2000; 19(10):563-569.

2. EPPO. Phosphine fumigation of stored products to control stored product insects in general. Bulletin OEPP/ EPPO Bulletin. 2012; 42(3):498-500.

3. Rajendran S, Gunasekaran N. Effects of phosphine fumigant on stored products. Pesticide Outlook. 1995, 10-12.

4. Rajashekar Y, Reddy PR, Begum K, Leelaja BC, Rajendran S. Studies on Aluminium phosphide tablet formulation. Pestology. 2006, 41-45.

5. Talukder FA, Islam MS, Hossain, MS, Rahman MS, Alam MN. Toxicity effects of botanicals and synthetic insecticides on Tribolium castaneum (Herbst) and Rhizopertha dominica (F.). Bangladesh Journal of Environmental Science. 2004; 10(2):365-371.

6. Talukder FA. Insects and insecticide resistance problems in post-harvest agriculture. Proc Proceedings of International Conference on postharvest Technology and Quality Management in Arid Tropics, Sultan Qaboos University, Oman. 2005, 207-211.

7. Talukder, FA. Plant products as potential stored-product insect management agents- A mini review. Emirates Journal of Agricultural Sciences. 2006; 18(1):17-32.
8. Ahmed MEA. Fumigant toxicity of seven essential oils against the cowpea weevil, Callosobruchus maculatus (F.) and the rice weevil, Sitophilus oryzae (L.). Egyptian Academic Journal of Biological Sciences. 2010; 2(1):1-6.

9. Rajendran S. Status of Fumigation in stored grain on India. Journal of Grain Storage Research. 2016, 29-38.

10. Rajendran S, Gunasekaran N, Muralidharan N. Studies on phosphine fumigation of wheat bag stacks under different storage conditions for controlling phosphine resistant insects. Pesticide Research Journal. 2001; 13(1):42-47.

11. Rajendran S. Perfecting phosphine fumigations for food grain preservation and international trade in India. Proceedings of the 10th International Conference on Controlled Atmosphere and Fumigation in Stored Products.CAF Permanent Committee Secretariat, Winnipeg, Canada, 2016, 195-200.

12. Reddy PV, Rajashekar Y, Begum K, Leelaja BC, Rajendran $\mathrm{S}$. The relation between phosphine sorption and terminal gas concentrations in successful fumigation of food commodities. Pest Management Science. 2007; 63:96-103. 